\title{
Breast Cancer in Women of Younger than 35 Years: A Single Center Study
}

Umesh Das*, Lakshmaiah KC, Lokanatha D, Govind Babu K, Linu Jacob and Suresh Babu

Department of Medical Oncology, Kidwai Memorial Institute of Oncology, Banglore, Karnataka, India

\begin{abstract}
Aim: Breast cancer in women younger than 35 years old is uncommon and only accounts for $2 \%$ of all breast cancers diagnosed in Western countries. However, there is paucity of data on breast cancer in women younger than 35 years old in India. The aim of this study was to assess clinicopathological parameters in these young breast cancer patients.
\end{abstract}

Methods: This retrospective study summarized data on women younger than 35 years with breast cancer between August 2012 and July 2013 from tertiary cancer center in India.

Results: Out of a total of 320 patients, 36 were younger than 35 years old in this period of time and the median age was 32 years. A breast lump was the most commonly presented symptom with an average symptom duration of four months. The median age of the first childbirth was 22 years. Most of the patients had a stage III disease (52\%) followed by stage II (33\%). All patients had invasive ductal carcinoma and $86 \%$ of patients had high-grade tumors. $51 \%$ of patients were lymphnode-positive, and lympho vascular emboli were present in $43 \%$ of cases. Estrogen receptor (ER)/progesterone receptor (PR) and human epidermal growth factor receptor-2 (HER2) positivity occurred in $38.9 \%$ and $22.2 \%$ of patients, respectively and $50 \%$ of patients were triple negative.

Conclusion: Breast cancer occurring in women younger than 35 years old constituted $11.3 \%$ of all breast cancer cases in Kidwai Memorial Institute of Oncology, India. They had high tumor grade with a larger size and an increased incidence of lympho vascular emboli, which lead to aggressive behaviors and poor prognosis. This study suggest that early onset of breast cancer must be considered as a diagnostic possibility in Indian patients presenting palpable masses in the mammary glands.

Keywords: Breast cancer in young women; Invasive ductal carcinoma; triple negative; Lymphovascular emboli

\section{Introduction}

Breast cancer in women younger than 35 years old is uncommon and accounts for $2 \%$ of all breast cancer in the West [1]. In young women, breast cancer tends to be more aggressive, larger in size and possesses a poorer prognosis when compared to older women [2-4]. Young women tend to have more advanced disease [2-5]. Age is an independent prognostic factor even when size and nodal status are considered. Young aged patients have a worse prognosis than older one $[2,3]$. These patients have a higher incidence of invasive ductal carcinoma (IDC), a greater number of lymphnode-positive cancers, and are more likely to have lymphovascular invasion [4]. Young women are more likely to have tumors that are ER-negative [2,5,6]. Even though the frequency is low, breast cancer is the leading cause of cancer-related death in this age group, and survival rate of these young women is less than older patients [7]. Apart from the biological behavior of tumors, the lack of adequate screening and awareness is the major contributory factor in the larger and higher stage of cancer in this age group. Due to the relative infrequency of breast cancer in this group and the universal nature of the symptoms related to benign disorder of the mammary glands, tumor diagnosis is usually delayed, and thus contributes to advanced stages of this disease. There is a paucity of data on breast cancer in younger women in India. The aim of our study was to assess clinicopathological parameters in young women with breast cancer and provide future wellness or early detection.

\section{Methods}

This retrospective study was carried in a tertiary cancer center in India summarizing data collected between August 2012 and July 2013. Out of a total of 320 patients, we found 36 breast cancer patients younger than 35 years old treated during this period of time. Medical records of breast cancer patients were thoroughly reviewed and those cases with patients younger than 35 years were selected for the study. Diagnosis of breast cancer was primarily based on clinical presentation, imaging (mammogram, ultrasound of the breast), and histopathology. The staging was according to chest $\mathrm{x}$-ray and/or ultrasound with the addition of bone scans and computed tomographies for locally advanced disease and metastatic disease. Histopathology was reviewed and confirmed by two pathologists independently. Patients were staged in accordance with the American Joint Committee on Cancer 7 tumor node metastasis (TNM) staging system.

\section{Results}

\section{Patient characteristics}

A total of 320 breast cancer patients were registered in our center during this one-year period of time, 36 (11.3\%) of which were younger than 35 years old with a median age of 32 years (ranged between 22 and 34 years). Breast lump was the most commonly presented and the leftsided breast lump was more common than the right side. One patient was presented with a bilateral breast lump. The median duration of symptoms was four months (ranged between 1 and 24 months), while $75 \%$ of patients had symptoms lasting more than 60 days. The median

*Corresponding author: Umesh das, Department of Medical Oncology, Kidwai Memorial Institute of Oncology, Banglore-560029, Karnataka, India, Tel: 91-9577521134; E-mail: drumesh.das07@gmail.com

Received October 28, 2015; Accepted Novmber 22, 2015; Published Novmber 25,2015

Citation: Das U, Lakshmaiah KC, Lokanatha D, Babu G, Jacob L,Babu S (2015) Breast Cancer in Women of Younger than 35 Years: A Single Center Study. J Mol Biomark Diagn 6: 261. doi:10.4172/2155-9929.1000261

Copyright: (c) 2015 Das U, et al. This is an open-access article distributed under the terms of the Creative Commons Attribution License, which permits unrestricted use, distribution, and reproduction in any medium, provided the original author and source are credited. 
age of menarche was 13 years old (ranging between 11 and 15 years). $97 \%$ of patients were married and the median age of first childbirth was 22 years (18-30 years) with an average number of children of 2.11. Breast-feeding history was positive in $91.7 \%$ of the cases. There were 3 patients with nullipara in our study. Family history of breast cancer was elicited only in 1 case. Four patients had bilateral breast cancers, 3 of which had synchronous breast cancer ( possessing a second primary within 6 months of the first primary) and 1 had metachronous breast cancer (with more than 6 months since the first primary).

\section{Treatment of these patients}

Most of patients (31) were treated with modified redical mastectomy, and a bilateral modified radical mastectomy was performed in 3 patients (because of their synchronous bilateral breast cancer). Twelve patients received neoadjuvant chemotherapy before mastectomy due to locally advanced disease and five patients received fluouracil, epirubicin, and cyclophosphamide (5 fluorouracil, $500 \mathrm{mg} /$ $\mathrm{m}^{2}$, epirubicin, $100 \mathrm{mg} / \mathrm{m}^{2}$ and cyclophosphamide, $\left.500 \mathrm{mg} / \mathrm{m}^{2}\right)$, while 4 patients received fluorouracil, adriamycin and cyclophosphamide (5 fluorouracil, $500 \mathrm{mg} / \mathrm{m}^{2}$, adriamycin, $60 \mathrm{mg} / \mathrm{m}^{2}$ and cyclophosphamide, $500 \mathrm{mg} / \mathrm{m}^{2}$ ), and 3 patients received different chemotherapy regimens treatment.

\section{Tumor characteristics}

Most patients (52.8\%) had a stage III disease and $13 \%$ of patients had a stage IV disease. Most of the stage IV patients had multiple skeletal metastases. The TNM stage distribution is shown in Table 1. One patient had isolated malignant pericardial effusion, 2 patients had liver metastasis along with skeletal metastasis, and 1 patient had lung, liver and skeletal metastasis. IDC was diagnosed in all patients and $86.1 \%$ of tumors were graded as III and $13.9 \%$ as grade II. $51 \%$ of patients had lymph node metastasis, and lymphovascular emboli occurred in $43 \%$ of patients. ER/PR and HER2/neu positivity was found in $38.9 \%$ and $22.9 \%$ of cases, respectively (Table 2 ). $50 \%$ of patients had triple negative breast cancer.

\section{Discussion}

Breast cancer developing at a young age is commonly considered to be different from that of older women in perimenopause. Although breast cancer developing in women younger than 35 years old is rare and only accounts for $2 \%$ of all cases in the West [1], the incidence is much higher in Indian women our patient population. According to Mohanti et al. the incidence of breast cancer in young women less the 35 years was 5.5\% [8], and another study from India reported that breast cancer in young women aged 35 years or younger was $8 \%$ [9]. Anders et al. [10] reported relative incidence of $2.4 \%$ diagnosed before age 35 and $1 \%$ diagnosed before age 30. Sandhu et al. [11], reported from North India that $65.8 \%$ of patients with breast cancer were in the age group of 31-50 years. Although number of cases in the current study is small, our data showed a relative incidence of $11.3 \%$. A positive family history of breast or ovarian cancer is a very strong risk factor for women with breast cancer under 35 years of age [12] and suggested presence of a familial cancer syndrome. Breast cancer at an early age is more likely to be associated with increased familial risk, especially in women harboring germline Breast Cancer Susceptibility Gene-1 (BRCA1) mutations [13]. According to Lalloo et al. BRCA1, BRCA2 and tumor protein 53 mutations were found in approximately $50 \%$ of women with breast cancer diagnosed at an age younger than 30 years with a strong family history of breast cancer, and occurred in less than $10 \%$ of women without a history of familial breast cancer [14]. Patients with familial phosphatase and tensin homolog deleted on chromosome ten mutations also have an increased risk in an early onset of breast cancer [15]. However, in our current study, we only found 1 patient with a family history of breast cancer. This patient's elder sister had breast cancer at the age of 30 years, and she succumbed to the disease. Genetic testing was not done in due to financial constraints. Different studies have quoted various percentages of family history in young breast cancer patients. According to other 2 previous Indian studies, positive family history was respectively $4 \%$ and $5.53 \%$ in young breast cancer patients $[8,9]$. According to Walker et al. a positive family history of breast cancer occurs in $8 \%$ of cases with young breast cancer in patients less than 35 years of age [16]. Although family history was positive above mention studies but in present study only 1 patient family history of breast cancer.

Other risk factors of breast cancer in young women include a history of prior mantle irradiation for Hodgkin lymphoma, younger age at menarche, heavy alcohol consumption, and a high intake of red meat $[12,15,17]$. Intense physical activity and a high intake of certain fruits and vegetables have been associated with a decreased breast cancer risk in premenopausal women $[18,19]$.

Our study indicated that a breast lump was the most commonly presented symptom and the median duration of the symptoms to diagnosis was 4 months. $75 \%$ of patients had a delayed presentation (>60 days) which may have contributed to a larger tumor size. There are significant associations between delayed presentation and late stage disease [20]. Furthermore, our present study also showed that a high number of patients had a stage III disease followed by stage II, while stage IV disease occurred in $13 \%$ of patients. According to Raina et al. stage III tumor occurred in $55 \%$ of patients and stage IV in $22 \%$ [9]. Another Indian study showed similar results [8]. Colleoni et al. reported that $48 \%$ of patients had higher stage of disease [21]. Fredholm et al. [22] reported that breast cancer in young patients less than 35 of age was presented as a stage II disease. Histopathological evaluations have shown that most young breast cancer patients have IDC. Walker et al. reported that in all of his patients less than 35 years old, IDC was observed [16]. Other studies had also reported that IDC was the most common histological type in young females, accounting for $93 \%$ to $94 \%$ of cases $[8,9,16,21,22]$. Our study showed all patients had IDC as histological diagnoses.

Breast cancers in young women tend to be high grade with high proliferative index, high Ki67 index, high rate of lymph node positivity, perinodal spreads and lymphovascular invasion. In our current study, $86 \%$ of patients had an advanced grade tumor, i.e. $51 \%$ patients had lymph node metastasis and $43 \%$ patients had lymphovascular emboli,

\begin{tabular}{|c|c|}
\hline Stage & No of patients (Percentage) \\
\hline I & 0 \\
\hline II & $12(33 \%)$ \\
\hline III & $19(52.78 \%)$ \\
\hline IV & $5(13.88 \%)$ \\
\hline
\end{tabular}

Table 1: showing percentage of breast cancer, according to stage.

\begin{tabular}{|c|c|}
\hline Category & Percentage \\
\hline ER/PR positive & $38.88 \%(14)$ \\
\hline HER 2 positive & $22.0 \%(8)$ \\
\hline ER/PR+ HER2 positive & $13.8 \%(5)$ \\
\hline Triple negative & $50 \%(18)$ \\
\hline
\end{tabular}

Table 2: showing percentage of hormone receptors positive, HER2 neu positive and triple negative breast cancer. 
which is consistent with data reported in the literature [8,9,21]. Indian and Western studies reported high-grade tumors in young women, ranging from 24 to $71 \%$. Colleoni et al.[21] showed that $71 \%$ of patients had $\geq 20 \%$ positivity for Ki67 staining, while 2 Indian authors reported approximately $55 \%$ of lymph node metastasis in young breast cancer patients $[8,9]$ Node positive diseases were reported in Western studies ranging from $33 \%$ to $46 \%[16,21,22]$. Colleoni et al. showed $48 \%$ of cases with lymphovascular emboli [21].

In our current study, $50 \%$ of patients had a triple negative breast cancer, and ER/PR positive and HER2/neu positive cases occurred in $38.9 \%$ and $22 \%$ of patients, respectively. Two previous Indian studies reported triple negative disease rates of $31 \%$ and $33 \%$, respectively $[8,9]$ Colleoni et al. reported a very high incidence of ER/PR negative breast cancer in women with less than 35 years of age (Table 3)[21]. Breast cancer women younger than 35 years old constituted $11.25 \%$ of cases; this proportion is much higher than the published Western data of $1-2 \%$ and reflects the younger age of our population. These young groups of patients had high-grade and larger size tumors with increased lymphnode involvement and lymphovascular emboli, which indicate tumor aggressiveness and poor prognosis. Singh et al. [23] described that among early age onset of breast cancer, patients of Indian descent have the highest incidence of triple-negative breast cancer. In their study of 2,100 cases, Indian patients had higher incidence of triplenegative disease than African-Americans, followed by Hispanic, NonHispanic White and Chinese patients. The reason for the high incidence of triple negative disease among early onset breast cancer patients of

\begin{tabular}{|c|c|c|c|c|c|c|}
\hline & $\begin{array}{l}\text { Present } \\
\text { study } \\
(<35 y r s)\end{array}$ & $\begin{array}{l}\text { Mohanti } \\
\text { et al. [8] } \\
\text { (<35yrs) }\end{array}$ & $\begin{array}{l}\text { Raina } \\
\text { et al. [9] } \\
\text { ( } \leq 35 \mathrm{yrs})\end{array}$ & $\begin{array}{l}\text { Colleoni } \\
\text { et al. [21] } \\
\text { (<35yrs) }\end{array}$ & $\begin{array}{c}\text { Walker et } \\
\text { al. }(<35 \\
\text { yrs) [16] }\end{array}$ & $\begin{array}{c}\text { Hanna } \\
\text { Fredholm } \\
\text { et al. } \\
(<35 y r s) \\
{[22]}\end{array}$ \\
\hline$\%$ of patients & $11.25 \%$ & $5.5 \%$ & $8 \%$ & $13 \%$ & - & $2.1 \%$ \\
\hline $\begin{array}{c}\text { Stage } \\
\text { I } \\
\text { II } \\
\text { III } \\
\text { IV }\end{array}$ & $\begin{array}{c}0 \% \\
33.3 \% \\
52.8 \% \\
13.9 \%\end{array}$ & $\begin{array}{l}3 \% \\
20 \% \\
55 \% \\
22 \%\end{array}$ & $\begin{array}{c}3 \% \\
20 \% \\
55 \% \\
22 \%\end{array}$ & $48 \%$ & $\begin{array}{l}- \\
- \\
-\end{array}$ & $\begin{array}{l}26 \% \\
54 \% \\
11 \% \\
3.2 \%\end{array}$ \\
\hline HPE & $\begin{array}{l}\text { IDC } \\
100 \%\end{array}$ & IDC $94 \%$ & IDC93\% & - & IDC $100 \%$ & \\
\hline $\begin{array}{c}\mathrm{Er} / \mathrm{pr}+ \\
\mathrm{Her} 2+ \\
\text { Triple } \\
\text { negative }\end{array}$ & $\begin{array}{c}38.9 \% \\
22.2 \% \\
50 \%\end{array}$ & $\begin{array}{l}40 \% \\
37 \% \\
31 \%\end{array}$ & $\begin{array}{l}33 \\
30 \\
33\end{array}$ & $\begin{array}{c}\text { Er } \\
\text { neg38\%, } \\
\text { pr neg } \\
49 \% \\
39 \% \\
\mathrm{Na}\end{array}$ & $\begin{array}{c}\mathrm{Er}+57 \% \\
\mathrm{pr}+37 \% \\
22 \%\end{array}$ & $\mathrm{Er} / \mathrm{pr}+46$ \\
\hline $\begin{array}{c}\text { Grade } \\
\text { I } \\
\text { II } \\
\text { III } \\
\text { Ki } 67\end{array}$ & $\begin{array}{c}0 \% \\
13.9 \% \\
86.1 \% \\
-\end{array}$ & $\begin{array}{l}60 \% \\
\text { high } \\
\text { grade }\end{array}$ & $30 \%$ & $\begin{array}{c}8.2 \% \\
29.9 \% \\
61.9 \% \\
\mathrm{KI} 67 \\
\geq 20 \% \\
=71 \%\end{array}$ & $\begin{array}{c}0 \% \\
30 \% \\
70 \% \\
\text { low } 20 \% . \\
\text { medium } \\
13 \% \text {,high } \\
67 \%\end{array}$ & $\begin{array}{r}3 \% \\
8 \% \\
24 \%\end{array}$ \\
\hline $\begin{array}{c}\text { Pathological } \\
\text { node + }\end{array}$ & $51 \%$ & $56 \%$ & $55 \%$ & $\begin{array}{c}33 \%(1-3 \\
\text { node) } \\
10 \%>10 \\
\text { node }+\end{array}$ & $46 \%$ & $\begin{array}{c}43 \% \\
(1-3 \text { node } \\
25.1 \% \geq \\
\text { nodes } \\
18.5 \%)\end{array}$ \\
\hline LVE & $43 \%$ & - & - & $48 \%$ & & \\
\hline
\end{tabular}

HPE - Histopathological examination, IDC - invasive ductal carcinoma, LVElymphovascular emboli.

Table 3: Comparison of various Indian and western studies of breast cancer in young women.
Indian descent remains unknown, but this disparity has been observed in different studies. Despite its limited scope, this report is in line with the findings of Singh et al. From a public health point of view, these studies suggest that early onset of breast cancer must be considered as a diagnostic possibility in Indian patients presenting palpable masses in the mammary glands. Thus, better education and wellness for patients and their families for breast self-examination and clinical breast exam at routine health checkups should be warranted. Additionally, medical attention should be immediately encouraged or sought upon discovery of a breast mass.

\section{Conclusion}

Young women $<35$ years constituted $11.25 \%$ of breast cancer cases; this proportion is much higher than the published Western data of $1-2 \%$ and reflects the younger age of our population. These young groups of patients had high-grade tumors, larger size tumor, increased pathological node involvement and increased incidence of LVE, which indicates the aggressive clinical behavior and poor prognosis in these groups. Although triple negative was much higher ER PR positive case, and HER2neu positive cases were also seen in $38.8 \%$ and $22 \%$ respectively.

\section{References}

1. SEER Cancer Statistics Review, 1975-2012, National Cancer Institute Bethesda, MD, USA.

2. Bonnier P, Romain S, Charpin C, Lejeune C, Tubiana N, et al. (1995) Age as a prognostic factor in breast cancer: relationship to pathologic and biologic features. Int J Cancer 62: 138-144.

3. Gajdos C, Tartter PI, Bleiweiss IJ, Bodian C, Brower ST (2000) Stage 0 to stage III breast cancer in young women. J Am Coll Surg 190: 523-529.

4. Fisher CJ, Egan MK, Smith P, Wicks K, Millis RR, et al. (1997) Histopathology of breast cancer in relation to age. $\mathrm{Br} \mathrm{J}$ Cancer 75: 593-596.

5. Gillett D, Kennedy C, Carmalt H (1997) Breast cancer in young women. Aust N Z J Surg 67: 761-764.

6. Chung M, Chang HR, Bland KI, Wanebo HJ (1996) Younger women with breas carcinoma have a poorer prognosis than older women. Cancer 77: 97-103.

7. Adami HO, Malker B, Holmberg L, Persson I, Stone B (1986) The relation between survival and age at diagnosis in breast cancer. N Engl J Med 315: 559-563.

8. Mohanti BK, Raina V, Gogia A, Deo SVS, Shukla NK (2012) Young patients with breast cancer ( $<35$ years): Single-institution study of 194 patients from India. J Clin Oncol e11013.

9. Raina V, Gogia A, Mohanti BK, Deo SVS, Shukla NK (2013) Breast cancer in the young ( $=35$ years): A single center study from the All India Institute of Medical Sciences. J Clin Oncol e12539.

10. Anders CK, Johnson R, Litton J, Phillips M, Bleyer A (2009) Breast cancer before age 40 years. Semin Oncol 36: 237-249.

11. Sandhu DS, Sandhu S, Karwasra RK, Marwah S (2010) Profile of breast cancer patients at a tertiary care hospital in north India. Indian J Cancer 47: 16-22.

12. Althuis MD, Brogan DD, Coates RJ, Daling JR, Gammon MD, et al. (2003) Breast cancers among very young premenopausal women (United States). Cancer Causes Control 14: 151-160.

13. Antoniou A, Pharoah PD, Narod S, Risch HA, Eyfjord JE, et al. (2003) Average risks of breast and ovarian cancer associated with BRCA1 or BRCA2 mutations detected in case series unselected for family history: a combined analysis of 22 studies. Am J Hum Genet 73: 709.

14. Lalloo F, Varley J, Moran A, Ellis D, O'dair L, et al. (2006) BRCA1, BRCA2 and TP53 mutations in very early-onset breast cancer with associated risks to relatives. Eur J Cancer 42: 1143-1150.

15. Bleyer, A, O'Leary, M, Barr, R, Ries, L (2006) Cancer epidemiology in older adolescents and young adults 15 to 29 years of age, including SEER incidence and survival (1975-2000), National Cancer Institute, NIH Publication,USA. 
Citation: Das U, Lakshmaiah KC, Lokanatha D, Babu G, Jacob L,Babu S (2015) Breast Cancer in Women of Younger than 35 Years: A Single Center Study. J Mol Biomark Diagn 6: 261. doi:10.4172/2155-9929.1000261

16. Walker RA, Lees E, Webb MB, Dearing SJ (1996) Breast carcinomas occurring in young women (<35 years) are different. Br J Cancer 74: 1796-1800.

17. Cho E, Chen WY, Hunter DJ, Stampfer MJ, Colditz GA, et al. (2006) Red meat intake and risk of breast cancer among premenopausal women. Arch Intern Med 166: 2253-2259.

18. Do MH, Lee SS, Kim JY, Jung PJ, Lee MH (2007) Fruits, vegetables, soy foods and breast cancer in pre- and postmenopausal Korean women: a case-control study. Int J Vitam Nutr Res 77: 130-141.

19. Slattery ML, Edwards S, Murtaugh MA, Sweeney C, Herrick J, et al. (2007) Physical activity and breast cancer risk among women in the southwestern United States. Ann Epidemiol 17: 342-353.
20. Montazeri A, Ebrahimi M, Mehrdad N, Ansari M, Sajadian A (2003) Delayed presentation in breast cancer: a study in Iranian women. BMC Womens Health 3: 4.

21. Colleoni M, Rotmensz N, Robertson C, Orlando L, Viale G, et al. (2002) Very young women ( $<35$ years) with operable breast cancer: features of disease at presentation. Ann Oncol 13: 273-279.

22. Fredholm H, Eaker S, Frisell J, Holmberg L, Fredriksson I, et al. (2009) Breast cancer in young women: poor survival despite intensive treatment. PLoS One 4: e7695.

23. Singh M, Ding Y, Zhang LY, Song D, Gong Y, et al. (2014) Distinct breast cancer subtypes in women with early-onset disease across races. Am J Cancer Res 4: 337-352. 